Revista Culturas Jurídicas, Vol. 6, Núm. 15, set./dez., 2019

\title{
FORMAÇÃO CRÍTICA EM DIREITOS HUMANOS ATRAVÉS DA CLÍNICA JURÍDICA ${ }^{1}$
}

\section{FORMACIÓN CRÍTICA EN DERECHOS HUMANOS POR MEDIO DE LA CLÍNICA JURÍDICA}

\author{
Guillermo Luévano Bustamante ${ }^{2}$
}

Resumo: O modelo de formação em pesquisa e, em geral, de ensino "tradicional" ou dominante no campo jurídico é vertical, autoritário, memorístico e excessivamente verbalizado. Isso implica que a função dos alunos, normalmente, seja passiva, pouco reativa e principalmente receptiva. Há pouca incidência na execução de operações mentais e na execução de procedimentos jurídicos, tanto legislativos, administrativos, judiciais e até de investigação por parte daqueles que frequentam as salas de aula das Faculdades de Direito. Modelos recentes de formação em pesquisa e ensino do Direito estão comprometidos com formas mais interativas e proativas que demandam outras modalidades daqueles que ensinam no campo jurídico. Por exemplo, o modelo de ensino crítico que exige um método dialético e uma análise contextual dos processos jurídicos exige que os alunos tenham uma participação mais ativa. O litígio estratégico de uma clínica jurídica de direitos humanos não remedia radicalmente as injustiças, apenas é um paliativo na luta contra as desigualdades. Por si só, não compromete a ordem cultural patriarcal nem o modelo econômico capitalista, não substitui as lutas políticas e sociais, se ao acaso as acompanha, mas segue sendo uma disputa no jogo e com as regras do Estado ou das elites ou das classes dominantes. No entanto, apesar de suas limitações, pode servir como atrativo para as vítimas que buscam usufruir de seus direitos, e remediação de uma afetação na sua esfera legal ou vital.

Palavras-chave: Crítica jurídica, direitos humanos, educação clínica, México.

Resumen: El modelo de formación en investigación y, en general, de enseñanza "tradicional" o dominante en el campo legal es vertical, autoritario, memorístico y excesivamente verbalizado. Esto implica que el papel de los estudiantes es normalmente pasivo y principalmente receptivo. Hay poco impacto en la ejecución de operaciones mentales y la ejecución de procedimientos legales, tanto legislativos, administrativos, judiciales e incluso de investigación por parte de quienes asisten a las aulas de las Escuelas de Derecho. Los modelos recientes de formación en investigación y enseñanza del derecho están comprometidos con formas más interactivas y proactivas que exigen otras modalidades de quienes enseñan en el campo legal. Por ejemplo, el modelo de enseñanza crítica que requiere un método dialéctico y un análisis contextual de los

\footnotetext{
${ }^{1}$ Texto submetido em 26 de novembro de 2019 e aprovado em 27 de dezembro de 2019. Texto originariamente publicado em espanhol: Crítica jurídica y enseñanza clínica. La experiencia desde la Universidad Autónoma de San Luis Potosí. In: DÍAZ, Martín E. (Coord.). Geopolítica de los saberes hegemónicos. Estudios críticos para desandar el eurocentrismo/Carlos Pescader (Coord.), $1^{\mathrm{a}}$ ed. Aguascalientes-San Luis Potosí-General Roca: CENEJUSUASLPUNCo, 2019. Tradução para o português realizada pelo próprio autor.

${ }^{2}$ Doutor em Ciências Sociais com especialidade em Antropologia Social pelo Centro de Investigación y Estudios Superiores en Antropología Social (CIESAS), México. Professor na Universidad Autónoma de San Luis Potosí, México. ORCID: https://orcid.org/0000-0003-2619-1557. E-mail: guillermo.luevano@gmail.com.
} 
procesos legales requiere que los estudiantes tengan una participación más activa. El litigio estratégico de una clínica jurídica de derechos humanos no remedia radicalmente las injusticias, es solo un paliativo en la lucha contra las desigualdades. Por sí solo, no compromete el orden cultural patriarcal o el modelo económico capitalista, no reemplaza las luchas políticas y sociales, si las acompaña, pero sigue siendo una disputa en el juego y con las reglas del Estado o de las élites y clases dominantes. Sin embargo, a pesar de sus limitaciones, puede servir como un medio para las víctimas que buscan acceder a sus derechos y remediar una afectación en su esfera legal o vital.

Palabras clave: Crítica jurídica, derechos humanos, educación clínica, México.

\section{Introdução}

O que chamamos de ensino "tradicional" do Direito, geralmente, significa um modelo de ensino unilinear que privilegia a exposição de professores "expertos" e no qual o corpo discente é um simples receptor, com pouca participação ativa. A habilidade predominante que se espera que os alunos cumpram é a memorização de conteúdos que quase sempre são os mesmos sistemas normativos, com pouca reflexão teórica e, acima de tudo, com escassa vinculação do campo jurídico com a sociedade.

Além disso, o contexto da globalização econômica predispôs às instituições públicas de ensino superior que as disciplinas de Direito se orientem com o fim de atender aos requisitos do “mercado de trabalho" e, portanto, a formação de profissionais é regida por perfis empresariais.

No programa de mestrado em Direitos Humanos da Universidade Autônoma de San Luis Potosí, México, foi implementado um modelo de ensino teórico e prático desse campo, no qual estudantes de pós-graduação participam, auxiliando um professor na formação de estudantes de graduação. Este projeto se baseia na vinculação dos alunos com processos sociais ativos e exige que eles desenvolvam habilidades específicas, não apenas de conhecimento técnico do Direito, mas principalmente sociais, para a postulação de casos judiciais relevantes. Os resultados são altamente satisfatórios e contribuem para a especialização de seus participantes, os quais aprendem fazendo e, ao mesmo tempo, se vinculam com as comunidades vítimas de afetações aos seus direitos humanos. Este texto recupera algumas das experiências no ensino de Direitos Humanos com uma perspectiva crítica a partir de um modelo clínico. 


\section{Ensino jurídico clínico}

O modelo de formação em pesquisa e, em geral, de ensino "tradicional" ou dominante no campo jurídico é vertical, autoritário, memorístico e excessivamente verbalizado (WITKER, 2002, p. 188). Isso implica que a função dos alunos, normalmente, seja passiva, pouco reativa e principalmente receptiva. Há pouca incidência na execução de operações mentais e na execução de procedimentos jurídicos, tanto legislativos, administrativos, judiciais e até de investigação por parte daqueles que frequentam as salas de aula das Faculdades de Direito.

Modelos recentes de formação em pesquisa e ensino do Direito estão comprometidos com formas mais interativas e proativas que demandam outras modalidades daqueles que ensinam no campo jurídico. Por exemplo, o modelo de ensino crítico que exige um método dialético e uma análise contextual dos processos jurídicos exige que os alunos tenham uma participação mais ativa (HERNÁNDEZ, 2008, p. 198).

Uma das modalidades que propõem formas de ensino para a pesquisa jurídica crítica é o litígio estratégico (CORREA MONTOYA, 2008, p. 149-162), aplicado ao campo dos Direitos Humanos se traduz numa postulação complexa, que permite que os alunos se envolvam na pesquisa-ação do campo jurídico, mas com uma abordagem complexa.

Segundo Juan Carlos Gutiérrez (2011), o principal antecedente desse tipo de exercício é atribuído ao americano Jerome Frank, quem pensou na necessidade de vincular o ensino com o exercício do Direito.

O contexto em que Frank (nos Estados Unidos, em 1933) formulou a sua proposta teórico-prática para o Direito coincide com a chegada do que conhecemos como "realismo jurídico", uma perspectiva filosófica que reconhece a influência de fatores sociais, econômicos e culturais na criação e aplicação do sistema normativo, em oposição à tradição positivista que concebe o Direito a partir de uma posição puramente legalista que desloca ou minimiza a influência de componentes metajurídicos na conformação da legislação e sua aplicação.

Na defesa "comum", o advogado procura colocar a lei em favor de seu cliente; em uma clínica de contencioso estratégico, se busca mudar de forma radical o Direito para que tenha um impacto na sociedade, transformando a legalidade para que repercuta em casos futuros, para estabelecer precedentes e visibilizar temas excluídos da agenda pública.

O ensino e a prática jurídica através de uma clínica também garantem que os alunos que participam deles adquiram habilidades profissionais e entendam o Direito como uma ferramenta 
de mudança social e como possível promotor de políticas públicas de inclusão e não de discriminação, como, geralmente, sucede com grupos populacionais que não têm o pleno reconhecimento de seus direitos, tais como os povos indígenas, as pessoas com deficiência ou os migrantes. Por esse motivo, é comum que o ensino prático jurídico esteja diretamente ligado à defesa dos Direitos Humanos, embora seja desejável que outras áreas entrem no modelo.

Por essa razão, também é comum que as clínicas jurídicas universitárias incorporem como parte de seu trabalho o litígio estratégico, paradigmático ou de interesse público ou apenas causas, que podem ser definidas como a prática jurídica que busca "a expansão dos direitos" (MORALES, 2011, p. 160).

O trabalho dessas clínicas é interdisciplinar, como se verá, uma vez que aqueles que nela colaboram lhes ajudam as ferramentas conceituais da ciência política, sociologia, antropologia, psicologia, história.

O litígio de interesse público compreende, por sua vez, várias estratégias, de acordo com a Rede Latino-Americana de Clínicas Jurídicas (s/d/):

1. Jurídica. Em que são identificados os sujeitos, os direitos humanos violados e as ações a serem realizadas;

2. Social. Por meio do qual são reconhecidos os sujeitos sociais e as repercussões coletivas que o caso implica;

3. Política. Que tende a identificar as instituições aliadas e as de possível atenção do caso;

4. Educacional. Em que se trata de documentar o caso, capacitar o pessoal envolvido e extrair lições para situações futuras;

5. Segurança. Isso serve para ponderar os possíveis riscos de defesa jurídica e também as deficiências dos sistemas de prestação e obtenção de justiça, por exemplo, o impacto da corrupção, burocratização, falta de treinamento do pessoal da administração pública, etc.

Essas atividades significam que o litígio estratégico não é resolvido somente nos fóruns ou tribunais e não apenas por meios estritamente processuais, mas com o auxílio de argumentos acadêmicos e com o acompanhamento de organizações da sociedade civil.

O litígio estratégico pode resultar na modificação da legislação local ou nacional; na definição de critérios jurisprudenciais; no desenho e implementação de políticas públicas; ou, de um modo geral, na geração de uma cultura de direitos humanos como insumo na construção de um Estado Social de Direito. Também a práxis dos Direitos Humanos na modalidade de litígio estratégico mostra como a sociedade civil pode reverter o papel dominante do direito por uma função libertadora e garantidora dos direitos fundamentais. 
O litígio estratégico não remedia todas as injustiças do modelo econômico capitalista ou do sistema patriarcal, mas ajuda a remediar situações emergentes e necessárias, através do uso de instrumentos jurídicos, políticos, acadêmicos, nacionais e internacionais e põe em prática o conhecimento dos estudantes de Direito a serviço de grupos populacionais empobrecidos ou jurídica e socialmente mais vulneráveis.

A história do ensino prático jurídico como conhecemos hoje é recente. E se costuma admitir que a primeira onda de ensino jurídico clínico ocorreu nos Estados Unidos, Canadá, Austrália e Grã-Bretanha, em um contexto marcado pelo ativismo social da década de 1960 e pelas demandas de acesso à justiça em grandes setores marginalizados (GIDDINGS, 2013, p. 56). Embora, o movimento tenha sido apresentado em praticamente todos os continentes.

Na América Latina, o ensino clínico teria começado na mesma época, a intensa década de 1960, com o patrocínio de várias iniciativas, como o "Movimento pelo Direito e o Desenvolvimento" e com o financiamento da Agência estadunidense para o Desenvolvimento Internacional (USAID) (CASTRO-BUITRAGO, 2013, p. 137). Por razões semelhantes, foi desenvolvida a educação clínica na região, primeiro em Porto Rico (1952) e na Guatemala (1954) (ORTIZ SANCHÉZ, 2005, p. 45), mas principalmente na Argentina, Colômbia, Chile e México, em contextos de autoritarismo contestado nas ruas e nos tribunais.

No México, as instituições acadêmicas pioneiras na incorporação do ensino clínico foram o Centro de Pesquisa e Ensino Econômico e o Instituto Tecnológico Autônomo do México (ITAM) em 2003 (CASTRO-BUITRAGO, 2013, p. 152). Atualmente, existem Clínicas Jurídicas também na Universidade Ibero-americana, na Universidade Michoacana de San Nicolás de Hidalgo, na Universidade Nacional Autônoma do México, na Universidade Autônoma de Nuevo León e na Universidade Autônoma de San Luis Potosí, sobre a qual aprofundaremos um pouco.

\section{Educação popular em direitos humanos}

É verdade que outras formas de transmitir/gerar/construir de conhecimento sobre os próprios direitos já foram exploradas há muito tempo. A educação popular americana tem uma referência fundamental em Paulo Freire (2005), com seu compromisso com uma pedagogia dos oprimidos e com as práticas de educação popular. E, como há, um reconhecimento de que esses modelos educacionais estão comprometidos com um exercício político de cidadania e direitos, é 
claro que constitui uma referência não apenas da educação em geral, mas da educação no campo dos direitos humanos.

No entanto, embora reconheça a necessidade de fortalecer e continuar promovendo a educação popular em direitos humanos, o caso aqui apresentado refere-se a um modelo pedagógico realizado pelas próprias universidades e que tem seu principal apoio no corpo discente, o qual é formado na educação popular para exercer modos de educação horizontal e solidária. Desse modo, há uma clara influência da educação popular nos direitos humanos na operação do caso da Clínica Jurídica que será apresentada, mas não vou me referir precisamente à pedagogia dos oprimidos.

De muitas maneiras, a educação popular em direitos humanos passa pelo exercício do que é feito no caso específico a que me referirei abaixo, admitindo o potencial descrito em seguida:

La educación popular en derechos humanos potencia el juicio como una facultad política que nos permite distinguir, relacionar, debatir, exigir, deliberar y sobre todo, imaginar para poder ir y venir de los otros al sí mismo y viceversa, reproduciendo el espacio común de un diálogo que garantiza la validez de la propia opinión. Quien juzga tiende a «ponerse en el lugar de cada uno de los otros», logrando un «pensar amplio», es decir, logrando «empinarse por sobre las condiciones subjetivas privadas del juicio» y reflexionar sobre su propio juicio desde un punto de vista universal. La educación popular en derechos humanos promueve una cultura del juicio, es decir, unas prácticas sociales que insisten en la colocación de argumentos, la posibilidad de rebatir, mostrar acuerdos y discrepancias; así como la capacidad de persuadir o ser convencidos porque se asume la facultad de juicio como un elemento central de la competencia de la ciudadanía o mejor dicho, como patrimonio de la ciudadanía. La educación popular en derechos humanos faculta a los sujetos para colocar en el foro público, de forma argumentada y razonada, aspectos de la vida personal/social, pública/privada que a todos incumba y que puedan ser sometidos al escrutinio público, desmitificando la vida privada, favoreciendo así la democracia deliberativa. (EL ACHKAR, 2009).

Mas, o espaço clínico segue diretrizes um pouco mais rígidas que a proposta freireana de inspiração, como será visto.

\section{Educação jurídica clínica e crítica}

Nem toda formação clínica jurídica é, por si só, ensino crítico. Em seu livro La enseñanza del derecho como forma de acción política, Duncan Kennedy (2012) compartilha algumas de suas experiências como professor da Universidade de Harvard ao tentar transmitir noções teóricas e empíricas que revelam o caráter político das normas jurídicas. $\mathrm{O}$ cenário 
apresentado é complexo: pouca receptividade em seus alunos, críticas a seus colegas e, em geral, um ambiente institucional adverso. O professor americano sustenta que as Faculdades de Direito são, em geral, instituições do sistema capitalista e burocrático (KENNEDY, 2012, p. 50), e que, portanto, são espaços nos quais a resistência deve se opor.

O livro apoia uma tese: o núcleo doutrinário do direito privado tem uma orientação ideológica identificada com as direitas ou, ao menos, com a centro-direita, enquanto outras expressões do campo jurídico se distanciam dessa perspectiva e até se aproximam de um tipo de práxis esquerdista. Entre as possíveis aplicações do Direito que se distanciam da centro-direita do direito privado, Kennedy (2012, p. 16-24) identifica os estudos políticos, o direito público, o processual, a abordagem interdisciplinar e a formação clínica. Com esta última, em particular, ele estabelece uma relação com formas críticas de entender o Direito e de formar profissionalmente os alunos nesse campo. Dada à origem do ensino clínico, na qual se tentou mostrar aos estudantes de Direito como os setores mais vulneráveis da sociedade vivem, entendem e sofrem com o sistema judiciário, isso pode produzir certo nível de sensibilidade e conscientização nos futuros profissionais do Direito. Nem sempre é esse o caso, mas uma posição crítica pode ser obtida mais facilmente na educação clínica do que na educação universitária "tradicional", como mencionamos anteriormente.

A palavra crítica no campo das Ciências Sociais é uma categoria polissêmica. Kant e Marx, entre outros se dedicaram profusamente a ela. Várias escolas e tradições acadêmicas são rotuladas para se identificarem, por isso solicito uma consideração para não interromper a discussão do presente texto neste momento (LEAL CARRETERO, 2003). Entre as múltiplas derivações possíveis, pela compreensão crítica do Direito, seu ensino e seu exercício, me referirei aqui à perspectiva que questiona o paradigma kelseniano simplificador do Direito, como Rosillo Martínez (2019, p. 87) o entende, como um distanciamento do enfoque hegemônico da racionalidade moderna.

Assim, quando fale aqui de uma educação crítica do Direito, estarei me referindo às formas de ensinar essa profissão, revelando seu caráter político, sociocultural e histórico, enfatizando que é muito mais que um sistema de normas formais e escritas, uma prática e uma série de relações dos integrantes de uma comunidade com base nas suas disputas pela justiça. E ainda mais, que esse conceito está associado à práxis de comunidades específicas das quais se 
nutre e as que podem - e talvez devem - retroalimentar para contribuir com seus processos emancipatórios.

Assim, entendida a abordagem crítica do Direito, é normal que não se encontre como objetivo de nenhum currículo do pensum das Faculdades de Direito, é antes uma maneira externa de buscar a prática jurídica, em diálogo aberto com comunidades carentes. Frequentemente, em todo caso, nas instituições de ensino jurídico se costuma associar o Direito com a preservação do status quo, da ordem vigente, do modelo do livre comércio, da preservação da desigualdade econômica, de certo respeito pelas elites políticas e a classe dominante, apesar do discurso fictício - da igualdade jurídica.

\section{A abordagem sociocultural na crítica jurídica da tradição latino-americana}

Anteriormente mencionei, seguindo Duncan Kennedy, que uma das maneiras de se desapegar da rigidez do núcleo doutrinário, ideológico e politicamente vinculado à direita, do direito privado é o tratamento interdisciplinar. Especialmente, a Sociologia e a Antropologia ajudam a vacinar o direito de seu formalismo positivista excessivo. No uso e recorrência dessas referidas disciplinas para a compreensão e articulação complexas do direito, prefiro uma denominação que as combine e que chamarei de "abordagem sociocultural do direito".

Jesus Antonio de la Torre Rangel (1997) identificou as vantagens da Sociologia Jurídica para a formulação de uma crítica jurídica latino-americana, como ele mesmo e Oscar Correas projetaram no México e, no Brasil, Miguel Pressburger e Antonio Carlos Wolkmer, entre outros.

Serve também que a abordagem social e cultural do direito para obter o que, a partir do pensamento político do mesmo De la Torre Rangel, foi chamado de "uso alternativo do Direito", este é o uso das juridicidade vigente a favor das pessoas pobres. Entendendo como "pobres" aos agentes e movimentos sociais que legitimariam as novas juridicidades, que exercem com suas práticas modalidades libertárias dentro do sistema normativo (WOLKMER, 1992).

O uso alternativo do Direito procura, então, coadjuvar com as causas dos grupos sociais retirados da titularidade de direitos do próprio sistema normativo por razões políticas, econômicas ou pelo desenho estrutural das leis e instituições que dificultam seu pleno acesso, seja mediante burocracias, normas que são expressas em linguagem técnica ou em jargões especializados e práticas que são estranhas e incompreensíveis para eles. 
Esta é, claramente, uma contribuição da Sociologia Jurídica ao campo disciplinar que é defendido neste texto para contribuir para uma função que Boaventura de Sousa (2007) chama de emancipatória, ou que possibilita a criação de formas de legalidade "a partir de baixo". O Direito moderno havia definido para o Estado a função de criação e aplicação da lei. A abordagem sociocultural do direito contribui para a desestatização do sistema de regras para aproximá-lo da sociedade.

A noção é disruptiva porque controverte os ensinamentos clássicos da formação positivista do Direito, nas que, como dissemos, Estado e Direito só eram possíveis entre si e de qualquer forma o sistema jurídico servia para reproduzir a ordem estabelecida. Ainda que já tenha sido dito que, aos poucos, a sociedade vem recuperando, através de lutas emancipatórias na América Latina, a capacidade criativa das normas que regulam a vida social, recorrendo à tradição dos povos nativos, aos pressupostos éticos comunitários e à própria legalidade positivada nacional e ainda internacional.

Os alcances da crítica jurídica e do uso alternativo do Direito não são menores. Não se trata apenas de subverter o controle absoluto do Estado sobre a legalidade, mas de fornecer, a partir dessa perspectiva, à sociedade uma capacidade criativa e reprodutiva de seus modos de vida, para que o Direito seja então mais legítimo e menos coercitivo. Enquanto isso, serve pelo menos para conter as violências estatais expressas na lei, em sua instrumentação, nas instituições e nas decisões políticas de seus operadores.

\section{Reformas judiciais recentes, novos cenários}

O México está passando por um período de mudanças em seu sistema jurídico, principalmente orientado por uma política econômica de livre comércio e coberto desde o sexênio 2012-2018 por um acordo nacional chamado "Pacto por México" e do qual se desprenderam modificações constitucionais incomuns emitidas pelo consenso das que, em 2012, eram as três principais expressões partidárias, Partido Revolucionário Institucional (na época o oficial), Partido de Ação Nacional e Partido da Revolução Democrática: Reforma Energética, Trabalhista, Fiscal, Educativa (MEXICO, 2012). Essas modificações legais comprometeram os direitos sociais vigentes ao longo do século $\mathrm{XX}$, reduziram os direitos trabalhistas, introduziram um modelo educacional que precariza as condições de atuação e desempenho dos professores, 
permitiram a entrada da iniciativa privada nacional e estrangeira em hidrocarbonetos, setor anteriormente reservado exclusivamente para intervenção pública. O governo federal entrante, com expectativas muito altas na reorientação do modelo econômico e na reconfiguração das relações entre sociedade e governo, sobretudo devido à necessidade de estabelecer a paz em um país atingido pela violência criminal, tráfico de drogas e corrupção, foi incapaz de conter essas expressões dilacerantes de uma profunda crise política e social.

Nada obstante, nos últimos anos também foram aprovadas reformas legais que introduziram novos mecanismos para a defesa dos direitos humanos. Um ano antes, em junho de 2011, foi aprovada uma reforma constitucional que, entre outras coisas, modificou a noção então vigente de "garantias individuais" pela de "direitos humanos", consolidando duas novas figuras no México: o bloco de constitucionalidade e o princípio da convencionalidade (MEXICO, 2016). Além disso, em 2013, se reformou a Lei que regula a ação de amparo $^{3}$ (equivalente ao mandado de segurança, no Brasil), que é uma figura emblemática da proteção dos direitos fundamentais no México. Essa modificação implica, entre outras coisas, que o juízo de amparo (que costumávamos chamar de juízo de garantias) proceda contra indivíduos quando eles atuam como autoridades e cujas funções derivam de uma lei geral. Uma noção que de certa forma reúne a proposta de "efetividade horizontal dos direitos humanos" (ANZURES GURRÍA, 2010), ou seja, o reconhecimento de que já que entre particulares existem exercícios de poder, às vezes excessivos e quase sempre desiguais, é possível falar sobre violações de direitos humanos cometidos por um ente privado. Também se abriu a discussão para uma compreensão mais complexa dos graus de afetação à esfera jurídica de uma pessoa, ou coletividade, com a inclusão na Lei da noção de "interesse legítimo", que possibilita a interposição de uma ação judicial de direitos humanos ante violações eventuais e indiretas, ao contrário da ideia de "interesse jurídico" que exigia de quem promovia uma ação desse tipo para que a afetação fosse direta e consumada, por exemplo. Esses critérios, como os anteriores sobre direitos humanos, ainda são debatidos entre especialistas doutrinários, candidatos e até entre membros do Judiciário.

Esse contexto é o que tem possibilitado uma maior articulação de litígios estratégicos, ainda que a Suprema Corte de Justiça da Nação tenha sido errática ao reconhecer seus alcances e

\footnotetext{
${ }^{3}$ Ley de Amparo, regulamentação dos artigos 103 e 107 da Constituição Política dos Estados Unidos Mexicanos. Nova Lei publicada no Diário Oficial da Federação em 02 de abril de 2013.
} 
possibilidades. Às vezes, ela reconhece benefícios sobre assuntos de um tipo e, às vezes, nega a proteção da justiça sob critérios excessivamente formalistas.

\section{A Clínica Jurídica da Universidade Autônoma de San Luis Potosí}

Desde janeiro de 2014, funciona na Pós-graduação da Faculdade de Direito da Universidade Autônoma de San Luis Potosí uma Clínica de Litígio Estratégico vinculada ao Programa de Mestrado em Direitos Humanos, que também envolve as Faculdades de Ciências Sociais e Humanas e de Psicologia (UASLP, s/d(b)).

Uma clínica de litígio estratégico universitária é, como já foi dito, uma forma de promover e defender os direitos humanos de um modo integral e desde uma abordagem interdisciplinar. Nela se revisam casos relevantes de violações de direitos fundamentais que implicam um interesse peculiar tanto pela documentação e pela pesquisa com fins acadêmicos como para o estabelecimento de precedentes jurídicos que possam contribuir para visibilizar uma omissão legislativa, uma política pública ou uma prática ou procedimento administrativo que desconsideram a aplicação dos direitos humanos do sistema jurídico nacional ou internacional.

O modelo dessa clínica permite e incentiva que os estudantes de Direito aprendem, com casos práticos reais, diferentes maneiras de entender e exercer sua profissão. Nesse tipo de espaços, se atendem casos não tradicionais de litígios que poderiam ser uma questão de direito comum. Trata-se de fortalecer os laços com as vítimas ou comunidades de vítimas de violações dos direitos humanos, fornecer assessoria e apoio jurídicos a grupos vulneráveis, excluídos do sistema normativo positivo e brindar apoio na elaboração de iniciativas para reformas legislativas que visem o reconhecimento dos direitos humanos.

Esta clínica é um mecanismo que põe em prática a postulação de causas de interesse público ou social e promove a reflexão teórica jurídica. Por meio do litígio estratégico se gera um maior grau de conscientização social nos estudantes e profissionais do Direito, assim como a interação com casos reais que envolvem violações dos Direitos Humanos, contribui para fortalecer o vínculo entre a teoria e a práxis e aponta para a continuação de um tipo de legalidade emancipatória, colocam as leis a serviço de grupos tradicionalmente excluídos das normas vigentes. 
De 2014 a 2019, participaram do projeto 57 alunos, 44 de graduação e 13 de mestrado, dos quais 11 são de países como Colômbia, Brasil ou Cuba. Além do coordenador da Clínica, o Coordenador do Mestrado em Direitos Humanos do qual o projeto depende, além de um professor e uma professora pós-doutorandos.

A Clínica tem assessorado mais de 100 assuntos em colaboração com mais de 20 organizações sociais de San Luis Potosí e de México, além de buscar uma estreita colaboração com um centro de pesquisa da entidade El Colegio de San Luis.

O modelo de pesquisa-ação com o qual trabalha implica que os estudantes realizem o trabalho de campo com frequência, com atividades colaborativas com as comunidades obtém informações, informamos o progresso judicial, participam de fóruns e espaços acadêmicos e militantes, frequentam campanhas de divulgação.

A Clínica obteve diversos financiamentos para o início de um programa de contribuição para a pesquisa da Secretaria da Educação Pública; depois um interno da própria universidade; também se tem beneficiado de contratos para consultorias que concedem bolsas de estudo a estudantes, o El Colegio de San Luis, o Fundo das Nações Unidas para a População, de organizações sociais e, recentemente, da União Europeia, por meio de um projeto de intervenção.

A forma de organização e desenvolvimento do trabalho dentro da Clínica adota a vertente de um modelo de ensino complexo e circundante: o coordenador orienta, o aluno aprende direitos humanos fazendo diligências e práticas de campo, as comunidades aprendem seus direitos e também a utilizar o sistema de justiça local e nacional, mas também, estudantes e professores aprendem outras maneiras de entender e exercer a justiça comunitária.

Ao estar composta inteiramente por estudantes da graduação ou mestrado, a problemática apresentada à equipe da Clínica pela comunidade-grupo ou pessoa requer a tomada de uma posição diferente daquela que seria assumida por um escritório de advocacia tradicional. Sendo assim, a conceituação do problema nos termos próprios da comunidade-grupo exige uma resposta sui generis à estratégia jurídica a ser executada. Essa demanda sui generis requer não apenas um processo de aprendizado jurídico próprio da equipe de trabalho, senão também um processo de troca de informações com a comunidade-grupo para a materialização de seus interesses e expectativas, bem como as propostas desenvolvidas para a resolução do problema detectado. 
A Clínica de Direitos Humanos da UASLP prestou vários serviços, como já foi dito, desde consultorias às organizações internacionais, treinamento de funcionários públicos, realização de seminários de especialização e, acima de tudo, postulação judicial de casos de violações de direitos humanos, de população LGBTTTI + , de pessoas com deficiência, de migrantes, comunidades indígenas, camponeses, jovens, em defesa e pelo reconhecimento dos direitos das mulheres, em questões trabalhistas, ambientais e até em matéria de direito de família (UASLP, s/d/(a)).

Durante os anos de vigência do projeto desta Clínica Universitária, foram obtidas

valiosas sentenças favoráveis às comunidades indígenas, camponeses, pessoas migrantes e diaristas, entre outros. Existem resoluções emblemáticas que derivam de processos judiciais iniciados pela Clínica Jurídica.

\section{Considerações finais}

Uma das opções possíveis diante do formalismo excessivo do ensino "tradicional do Direito" é a educação jurídica clínica, que consiste em um modelo de formação teórica e prática que envolve os estudante de forma ativa. Por outro lado, a educação popular havia questionado os modos rígidos e pretensiosamente "apolíticos" de ensinar direitos.

Nem todo ensino clínico tem um componente crítico, desde a perspectiva dos estudos críticos em ciências sociais. Embora, exista alguma tendência ao ensino clínico do Direito de vincular-se com temas polêmicos e com a disputa pelo acesso à justiça para grupos empobrecidos, por isso geralmente se trabalha esse modelo com direitos humanos. É igualmente comum que o ensino clínico em direitos humanos conte com campos de conhecimento além do estritamente jurídico. A clínica jurídica também costuma estar associada ao litígio estratégico, que é um modo de postulação abrangente que busca visibilizar exclusões, desigualdades, impugnar juridicamente decisões públicas autoritárias, estabelecer precedentes judiciais ou incidir em políticas públicas ou reformas legislativas.

O litígio estratégico de uma clínica jurídica de direitos humanos não remedia radicalmente as injustiças, apenas é um paliativo na luta contra as desigualdades. Por si só, não compromete a ordem cultural patriarcal nem o modelo econômico capitalista, não substitui as 
lutas políticas e sociais, se ao acaso as acompanha, mas segue sendo uma disputa no jogo e com as regras do Estado ou das elites ou das classes dominantes.

No entanto, apesar de suas limitações, pode servir como atrativo para as vítimas que buscam usufruir de seus direitos, e remediação de uma afetação na sua esfera legal ou vital.

\section{Referências}

ANZURES GURRÍA, José Juan. La eficacia horizontal de los derechos fundamentales.

Cuestiones constitucionales - Revista Mexicana de Derecho Constitucional, México, n. 22, enero-junio, p. 3-51, 2010. Disponível em:

$<\underline{\text { https://revistas.juridicas.unam.mx/index.php/cuestiones-constitucionales/article/view/5904/0 > }}$. Acesso em 20 set. 2019.

BLOCH, Frank S. (ed.). El movimiento global de clínicas jurídicas. Formando juristas en la justicia social. México: Tirant Lo Blanch, 2013.

CASTRO-BUITRAGO, Erika et al. 5. La educación jurídica clínica en América Latina: hacia el interés público. In: BLOCH, Frank S. (ed.). El movimiento global de clínicas jurídicas. Formando juristas en la justicia social. México: Tirant Lo Blanch, 2013.

CORREA MONTOYA, Lucas. Litigio de alto impacto: Estrategias alternativas para enseñar y ejercer el Derecho. Revista Opinión Jurídica, Medellín, v. 7, n. 14, julio-diciembre, 2008, p. 149-162. Disponía em: <https://www.yumpu.com/es/document/view/17279456/litigio-de-altoimpacto-estrategias-alternativas-para-ensenar-y->. Acesso em 5 out. 2019.

DE LA TORRE RANGEL, Jesús Antonio. Sociología Jurídica y uso Alternativo del Derecho. Aguascalientes: Instituto Cultural de Aguascalientes, 1997.

DE SOUSA SANTOS, Boaventura. El derecho y la globalización desde abajo: hacia una legalidad cosmopolita. México: UAM, Cuajimalpa-Antrhopos, 2007.

EL ACHKAR, Soraya. Educación popular en derechos humanos: Una práctica educativa para el ejercicio de la ciudadanía. Revista de Pedagogía, Caracas, v. 30, n. 87, diciembre, 2009. 
Disponível em: $<$ http://ve.scielo.org/scielo.php?script=sci_arttext\&pid=S079897922009000200004>. Acesso em 22 ago. 2019.

FREIRE, Paulo. Pedagogía del oprimido. México: Ed. Siglo XXI, 2005.

GIDDINGS, Jeff et al. 1. La primera ola de la educación jurídica clínica moderna. Estados Unidos, Gran Bretaña, Canadá y Australia. In: BLOCH, Frank S. (ed.). El movimiento global de clínicas jurídicas. Formando juristas en la justicia social. México: Tirant Lo Blanch, 2013. GUTIÉRREZ CONTRERAS, Juan Carlos; CANTÚ MARTÍNEZ, Silvano; RINCÓN COVELLI, Tatiana. Litigio estratégico en derechos humanos: modelo para armar. México D.F.: CMDPDH, 2011.

HERNÁNDEZ, María del Pilar. Didáctica aplicada al derecho. México: UNAM - Porrúa, 2008.

LEAL CARRETERO, Fernando. ¿Qué es crítico? Apuntes para la historia de un término. Revista Mexicana de Investigación Educativa, Consejo Mexicano de Investigación Educativa, A.C. Distrito Federal, México, v. 8, n. 17, enero-abril, 2003.

MEXICO. Secretaría de Relaciones Exteriores. Pacto por México. 2012. Disponível em: $<$ https://embamex.sre.gob.mx/bolivia/images/pdf/REFORMAS/pacto_por_mexico.pdf $>$. Acesso em 17 jul. 2017.

MEXICO. Secretaría de Gobernación. ¿Qué sabes sobre \#DDHH y la Reforma Constitucional de 2011? 12/01/2016. 11 puntos clave para entender y ejercer tus derechos. Disponível em: $<\underline{\text { https://www.gob.mx/segob/articulos/que-sabes-sobre-ddhh-y-la-reforma-constitucional-de- }}$ 2011-11-puntos-clave-para-entender-y-ejercer-tus-derechos $>$. Acesso em 9 out. 2019.

MORALES, Diego Ramón. Hacia una vinculación más estrecha entre clínicas jurídicas, organizaciones de derechos humanos y acciones de litigio estratégico. La experiencia del Centro de Estudios Legales y Sociales de Argentina. In: Clínicas de derechos humanos. Una alternativa para la educación jurídica y la sociedad. México: Suprema Corte de Justicia de la NaciónEscuela Libre de Derecho, 2011. 
ORTIZ SÁNCHEZ, Ivan. La proyección social en las facultades de derecho. Aproximación comparativa en un grupo de universidades de América Latina. In: PEÑA JUMPA, Antonio (coord.). Proyección social del derecho y clínicas jurídicas en las Universidades de América del siglo XXI. Madrid: Dykinson, 2005.

PEÑA JUMPA, Antonio (coord.). Proyección social del derecho y clínicas jurídicas en las Universidades de América del siglo XXI. Madrid: Dykinson, 2005.

KENNEDY, Duncan. La enseñanza del derecho como forma de acción política. Buenos Aires: Siglo XXI, 2012.

RED LATINOAMERICANA DE CLÍNICAS JURÍDICAS. Litigio estrategico. s/d. Disponível em: $<$ http://www.clinicasjuridicas.org/litigio-estrategico.htm>. Acesso em 22 jan. 2014.

ROSILLO MARTÍNEZ, Alejandro. Crítica ideológica del derecho. Del paradigma simplificador kelseniano al pensamiento de la liberación. In: Idem; CUEVANO BUSTAMANTE, Guillermo Luévano. En torno a la crítica del derecho. San Luis de Potosí: CENEJUS - UASLP, 2019.

UNIVERSIDAD AUTÓNOMA DE SAN LUIS DE POTOSÍ (UASLP). Archivo de la Clínica de Litigio Estratégico de la Maestría en Derechos Humanos de la Universidad Autónoma de San Luis Potosí. s/d(a).

UNIVERSIDAD AUTÓNOMA DE SAN LUIS DE POTOSÍ (UASLP). Página de la Facultad de Derecho de la Universidad Autónoma de San Luis Potosí. s/d(b). Disponível em:

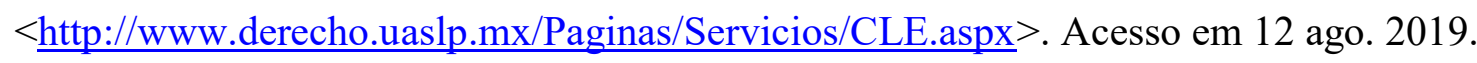

WITKER VELÁZQUEZ, Jorge; LARIOS VELASCO, Rogelio. Metodología jurídica. México: McGraw Hill, 2002.

WOLKMER, Antonio Carlos. Direito comunitário, globalização e cidadania. Sequência, estudos jurídicos e políticos, v. 20, n. 38, Florianópolis, p. 29-39, 1992. Disponível em:

$<$ https://periodicos.ufsc.br/index.php/sequencia/article/view/15508>. Acesso em 10 set. 2019. 